were sometimes very frequent. I could not ascertain from any of those resident in the neighbourhood the exact number in any definite time, but for several days they must have been almost hourly. The concussion was felt for a distance of four or five miles only around the focus of action; but it was so severe in the nearest village, that the people deserted their homes during its continuance.

On February I, at 4.30 P.M. we had a very long shock of earthquake, which was felt all over the group. It lasted within a few seconds of two minutes. The oscillation was very great. The islands seemed to be in the hands of Mafui'e (the earthquake god), and he shook us with a vengeance. I took my watch in hand when I felt the frrst indication of an earthquake, and sat for a minute amidst the clatter of windows, lamp-glasses, and every thing movable (a gentleman writing to me about it next day said his house seemed turned into a factory, with the clatter of machinery), but as it appeared to increase in severity, I deemed it prudent to go outside the house. I then noticed that the thatched roof $\mathrm{f}$ resented the appearance of waves running rapidly across from scuth to north. After it was over I found two clocks-one facing north, the other south-had been stopped; one facing west was still going. In three parts of my house the plaster at the angles of walls had been broken down. Bottles were thrown down and broken. In my study, books on a shelf facing north were shaken forward; those on shelves running north and south were not affected. The screw of a copying press, which I had used just before the earthquake, and which was standing tip at the time, had been run down. I found by experiment afterwards that it required a vigorous shake with both hands for half a minute to make the screw run down.

Iramediately after the earthquake I went to see if there was any oscillation of the sea. There was nothing perceptible on this-the north-side of the island. I have learned, however, from various sources that there was much oscillation on the routh side. Direcily after the shaking was over the reef was seen to be bare, and fish were lying exposed on it. The natives seen to be bare, and fish were lying exposed on it. The natives up they were overtaken by a wave, which would have proved fatal to many had they not been expert swimmers. I have heard of only one life lost-a child, who was found next day jammed between two masses of growing coral. It was low water at the time, but low.lying villages were flooded by the wave.

During the following night we had four slight shocks of earthquake, but have had nothing severe since.

Upolu, Samoa, April 3

\section{S. J. WhitmeE}

P.S.-I wish to correct a misprint in my letter on "The Degeneracy of Man," which appeared in NATURE, vol. xii. p. 47 . In speaking of the language of the Polynesians, I said there are many refinements, a large proportion of which are $u n$ known to most of the present generation. Unknown is, however, printed known, and thus the point of the illustration is lost.

Fauna and Flora of New Guinea and the Pacific Islands

I HAVE just read, with very great interest, some anthropological and zoological notes on a trip up the "Fly River" in New Guinea, by Signor D'Albertis. From these notes it appears lhat the "heaps of dung" which have been supposed to indicate the presence of a rhinoceros in the island, are probably the excrethe casuarius. Signor D'Albertis also reduces the "tracks of buffaloes" to those of wild hogs; and the fabulous bird "with a spread of wings of 16 feet" (which, in a former letter, I conjectured might have been a Casuarius, with proportionately large wings added by the imagination of the explorers under the influence of excitement), turns out to be nothing more than a Buccros quficollis with a spread of wings of " 4 or 5 feet."

$\mathrm{W}^{\top}$ e have, therefore, no reason for modifying our views as to the relation which the fauna of New Guinea bears to the rest of the world. Signor D'Alberlis mentions a few examples only of the New Guinea flora, but some of these are specifically identical with common South Pacific Island plants.

In connection with this subject, it may be interesting to some f your readers to know that $I$ have just entered into an arrangement with a Danish botanical collector-Mr. Fritz Jensenment with a Danish botan Samoa during the present month on a voyage 1 hrough the Union, Ellice, and Gilbert Islands
(Atolls), to collect for me in botany and zoology. On his return to Samoa in July, he will accompany me to the Loyalty Islands, where he will make a stay of four or five weeks collecting chiefly in botany. At the close of that period Mr. Jensen will proceed to the south-east coast of New Guinea (I have some hope of accompanying him), where he will spend about two months collecting.

Mr. Jensen has been residing with me for several months working at the Samoan flora, of which I have about 700 species in my collection. By the time he completes his trip I hope the collection will be of some value as material towards the preparation of a Flora of the Pacific Islands.

Samoa, April 3

\section{Optical Phenomenon}

I BEG leave to sind you a brief account of a striking atmospheric phenomenon which was visible in this neighbourhood on the evening of the $27^{\text {th }}$ ult. Hoping that some of your usual correspondents from the North of Ireland would have sent you a notice of it before this, I delayed writing to you (see vol. xiv. p. 23I).

The pheromeron consisted of a pillar of light which rose vertically from the horizon, over the spot where the sun, then set, presumably was at the time, and reached an altitude of some $8^{\circ}$, or perhaps more. I first saw it about 8.45 P.M., when the sun was set about a quarter of an hour, but it was, no doubt visible earlier, probably before sunset. As the sun moved under the horizon towards the north, the pillar moved in the same direction, still retaining its vertical position, but becoming gradually lower, until at last it disappeared about $9.40 \mathrm{P}$.M. the sun being then about $6^{\circ} 30^{\prime}$ below the horizon. The breadth of the pillar was equal to the apparent diameter of the sun. Its colour when first seen was a pale yellow, which as time advanced changed to a golden yellow, and finally to a deep red. The pillar was brighter near the horizon than at a greater altitude, and its uppe: end was not well defined, but gradually faded away. My son, who was with me, observed that the edges of the pillar were slightly scolloped. The sun had been clear and very hot during the day, but there was a cool air from the north-east, which became colder towaris sunset. I have heard that this pheno. menon was also visible at Portadown and Tynan, in the County Armagh, and at Aughnacloy in this county.

I presume there can be no doubt that the pillar consisted of a succession of images of the sun overlapping one another, but it is not easy to see how these images were produced. A nearly horizontal stratum of dense air, whose surfaces were slightly inclined to one another, with a rarer medium above and below, might form such a multiple image, by successive reflections and partial refractions at the lower surface, the sun.beam which fur. nished the direct or principal image to any observer, A, furnishing the second, third, \&c., images to observers behind him, so to speak, and sun-beams behind the former, successively furnish. ing $A$ with the images forming the upper part of the pillar.

I understand that German physicists. give this phenomenon the name of Sonnensänle-sun-pillar-and that they have pub. lished some speculations as to its origin. I hope some of your readers will kindly contribute information on this subject.

"Felix qui potuit rerum cognoscere causas."

Omagh, Co. Tyrone

R. V. D.

P.S.-Since writing abore I have learned that the "sun. pillar" was visible over a district of the north-east of Ireland, extending from Portrush in the north to Armagh in the south, and from Bangor (Belfast Lough) on the east to Omagh on the west. I have also heard from two intelligent correspondents that it was visible at sunset, when it attained an altitude of $30^{\circ}$; and from two others that it presented to them the appearance of being crossed by bands, alternately of a brighter and darlier shade,

\section{Freezing Phenomenon}

I HAVE waited to see whether anyone else would notice a letter that appeared in NATURE, vol. xiv. p. I9I, from $\mathrm{Mr}$. Power, under the above heading. Failing such notice, may I point out that the phenomenon to which he refers has already been described. Plumes produced by the crystallisation of water form the frontispiece to Dr. Tyndall's Lectures on Light (Longmans, 1873 ), and a description of them is given in p. 257 of that volume. 